\title{
The relationship between cardiac output and posthyperventilation hyperpnoea in patients with essential hypertension
}

\author{
S. Bellofiore*, L.S Malatino**, M.A. Sapienza*, I. Bellanuova**, A. Cataliotti**, G.U. Di Maria*
}

The relationship between cardiac output and posthyperventilation hyperpnoea in patients with essential hypertension. S. Bellofiore, L.S. Malatino, M.A. Sapienza, I. Bellanuova, A. Cataliotti, G.U. Di Maria. CERS Journals Ltd 1998.

ABSTRACT: Posthyperventilation hyperpnoea (PHVH) is the progressive decline in minute ventilation $\left(V^{\prime} E\right)$ that follows abrupt cessation of voluntary hyperventilation. It has been hypothesized that the increase in cardiac output $(\mathrm{CO})$ during hyperventilation could contribute to the duration of PHVH.

This hypothesis was tested by measuring the duration of PHVH in patients with essential hypertension, in whom the increase in $\mathrm{CO}$ as a result of various stimuli is less pronounced. Twenty male hypertensives (mean arterial blood pressure \pm SEM: 178/ $107 \pm 3 / 1 \mathrm{mmHg}$ ), and 12 age-matched male healthy subjects were studied. The study consisted of three periods: control $(5 \mathrm{~min})$, voluntary hyperventilation $(2 \mathrm{~min})$, and recovery $(3 \mathrm{~min}) . V^{\prime} \mathrm{E}, \mathrm{CO}$, end-tidal $\mathrm{CO}_{2}$ and $\mathrm{O}_{2}$ tensions were measured, and the time constant $(\tau)$ of the $V^{\prime} \mathrm{E}$ decay during recovery calculated.

The $V^{\prime} \mathrm{E}$ decay was faster in hypertensives $(\tau: 0-8.4 \mathrm{~s})$ than in healthy subjects $(\tau$ : $12-59 \mathrm{~s} ; \mathrm{p}<0.01)$. During voluntary hyperventilation, $\mathrm{CO}$ increased to a lesser extent in hypertensives $\left(6.8+0.7 \mathrm{~L} \cdot \mathrm{min}^{-1}\right)$ than in healthy subjects $\left(12.9 \pm 1.1 \mathrm{~L} \cdot \mathrm{min}^{-1} ; \mathbf{p}<0.01\right)$. In hypertensives, changes in $\mathrm{CO}$ during voluntary hyperventilation were significantly related to $\tau(r=0.646 ; n=20 ; p=0.002)$.

The less pronounced rise in cardiac output during hyperventilation in hypertensives could account for the shorter duration of posthyperventilation hyperpnoea. Eur Respir J 1998; 12: 1160-1163.
*Istituto di Malattie dell' Apparato Respiratorio and **Istituto di Clinica Medica L Condorelli, Universita' di Catania, Italy.

Correspondence: G.U. Di Maria

Istituto di Malattie dell' Apparato Respiratorio

Via Passo Gravina, 187

95125 Catania

Italy

Fax: 390957594532

Keywords: Cardiac output cardiovascular-respiratory interactions control of breathing essential hypertension hyperventilation

Received: August 191997 Accepted after revision February 71998
Following abrupt cessation of voluntary hyperventilation, ventilation declines gradually towards the baseline. This phenomenon has been called posthyperventilation hyperpnoea (PHVH), and it is believed to be due to the activation of a reverberating circuit of neurons in the respiratory centre area [1]. This reverberating circuit is activated along with the respiratory neurons and provides sufficient input to the respiratory centres to maintain ventilation after the decrease in chemoreceptor activity [1]. It has been demonstrated that different factors, such as the changes in arterial $\mathrm{pH}$ and $\mathrm{CO}_{2}$ tension $[2,3]$, blood progesterone levels [4], and respiratory frequency during hyperventilation [3], can affect the duration of PHVH.

It is well known that increases in cardiac output (CO) are followed by an increase in respiratory frequency and minute ventilation $\left(V^{\prime} E\right)$ in dogs $[5,6]$. However, there is evidence that during voluntary hyperventilation $\mathrm{CO}$ is substantially raised in healthy subjects $[7,8]$. Thus, it has been suggested that the increase in $\mathrm{CO}$ occurring during voluntary hyperventilation may affect the duration of PHVH [2]. It is also known that, in hypertensive patients, the increase of $\mathrm{CO}$ in response to exercise is less pronounced [9]. Therefore, if PHVH is influenced by the rise in $\mathrm{CO}$ during voluntary hyperventilation, hypertensive patients are expected to have a shorter duration of $\mathrm{PHVH}$, thus providing a model to study the determinants of the PHVH phenomenon in humans. To test this hypothesis, the duration of PHVH and the changes in $\mathrm{CO}$ during voluntary hyperventilation in patients with essential hypertension and in healthy subjects were assessed.

\section{Materials and methods}

We studied 20 male patients with essential hypertension (age range: 29-62 yrs) and 12 age-matched male healthy subjects (controls). Four hypertensives and two controls were current smokers. The mean values $( \pm$ SEM) of arterial blood pressure were 178/107 $\pm 3 / 1$ and $121 / 71 \pm 2 / 2 \mathrm{mmHg}$ in hypertensives and controls, respectively. Hypertensive patients belonged to stage I or II of the World Health Organization (WHO) classification and showed no concurrent illness, including respiratory tract disorders. Antihypertensive drugs were withdrawn $\breve{S} 4$ weeks before the study. Subjects were not allowed to drink beverages containing xanthines for $\breve{S} 24 \mathrm{~h}$ before the study. The study was approved by the Ethics Committee of the University of Catania, and each subject gave informed consent to participation in the study.

Subjects were seated and breathing through a face mask to which was attached a turbine flow head to measure airflow. A sampling line for the collection of end-expiratory gases was also connected to the face mask. After $10 \mathrm{~min}$ of quiet breathing, subjects were asked to perform sustained 
hyperventilation for a 2 -min period. The two-minute voluntary-hyperventilation period was started and stopped by verbal command. Subjects were free to regulate both tidal volume and respiratory frequency during the hyperventilation period. However, during the very beginning of the hyperventilation period, verbal instructions were given to adjust the level of hyperventilation in order to maintain end-tidal $\mathrm{CO}_{2}$ tension $\left(P \mathrm{ET}, \mathrm{CO}_{2}\right)$ as close as possible to 2.7 $\mathrm{kPa}$. This target was obtained within the first minute of voluntary hyperventilation in all study subjects. $V^{\prime} \mathrm{E}$, $P$ ET, $\mathrm{CO}_{2}$ and end-tidal oxygen tension were measured on a breath-by-breath basis with a computerized system (MMC 4400tc; SensorMedics, Yorba Linda, CA, USA). Measurements were performed during quiet breathing $(5 \mathrm{~min}$; control), during the two-minute voluntary-hyperventilation period and in the first $3 \mathrm{~min}$ of the recovery period. Meas-urements of $\mathrm{CO}$ were performed during control quiet breath-ing and during the last $30 \mathrm{~s}$ of voluntary hyperventilation. $\mathrm{CO}$ was measured noninvasively by the $\mathrm{CO}_{2}-$ rebreathing method [10]. Briefly, subjects inhaled at endexpiration a gas mixture containing $5 \% \mathrm{CO}_{2}$ and $21 \% \mathrm{O}_{2}$ in $\mathrm{N}_{2}$ and then rebreathed that gas mixture for $30 \mathrm{~s}$ in a twolitre bag. $\mathrm{CO}_{2}$ and $\mathrm{O}_{2}$ concentrations during the rebreathing were mea-sured breath-by-breath by fast-response (<200 ms) infra-red and zirconium analysers, respectively. Arterial blood pressure was recorded noninvasively (Dynamap 845; Dy-namap, Tampa, FL, USA) at baseline, during hyperventilation and during the recovery; the mean of three values obtained at each time interval was used for analysis.

The reproducibility of the PHVH was assessed by repeating the study after a two-hour interval in a subgroup of eight hypertensives and eight controls. The values for $V_{\mathrm{E}}^{\mathrm{t}}$ and of $P$ ET, $\mathrm{CO}_{2}$ were averaged for the control period and during the two-minute voluntary-hyperventilation period. During the recovery period, for each subject, $V^{\prime} \mathrm{E}$ was averaged every $10 \mathrm{~s}$. The first breath of recovery was calculated separately, but it was also included in the 0-10-s average. The time constant $(\tau)$ of the $V_{\mathrm{E}}^{\prime}$ decay over time $(t)$ during the recovery was calculated by fitting an exponential curve to the $V^{\prime} \mathrm{E}$ data: $V^{\mathrm{t}} \mathrm{E}(t)=\mathrm{gexp}(-t / \tau)$, where $\mathrm{g}$ is the magnitude of the first breath in the recovery period. The exponential equation was calculated by the least-squares method. Data are reported as mean \pm SEM. Differences in the two study groups were assessed by a two-sample ttest. Statistical significance was accepted for $\mathrm{p}<0.05$.

\section{Results}

Figure 1 shows the mean $\left( \pm\right.$ SEM) $V^{\prime}$ E measured at rest, during voluntary hyperventilation and in the recovery period in the two groups. The mean baseline value ( $( \pm \mathrm{SEM})$ of $V^{\prime} \mathrm{E}$ in hypertensive patients was $9.9 \pm 0.9 \mathrm{~L} \cdot \mathrm{min}^{-1}$, and did not differ from the corresponding values in normal subjects: $9.8 \pm 0.7 \mathrm{~L} \cdot \mathrm{min}^{-1}(\mathrm{p}=0.56)$. During the two-minute voluntary hyperventilation period, the average $V^{\prime} \mathrm{E}$ was also similar in hypertensive patients and controls $(74.7 \pm 2.6$ and $76.8 \pm 3.1 \mathrm{~L} \cdot \mathrm{min}^{-1}$, respectively). The respiratory frequency achieved during the last minute of voluntary hyperventilation did not differ in the two groups $(55.4 \pm 3.2$ and $56.9 \pm$ 3.7 breaths $\mathrm{min}^{-1}$, in hypertensives and controls, respectively). Resting $P$ ET, $\mathrm{CO}_{2}$ was $5.20 \pm 0.028$ and $5.17 \pm 0.023$ $\mathrm{kPa}$ in hypertensive patients and controls, respectively. During voluntary hyperventilation, $P$ ET, $\mathrm{CO}_{2}$ fell to $2.80 \pm$

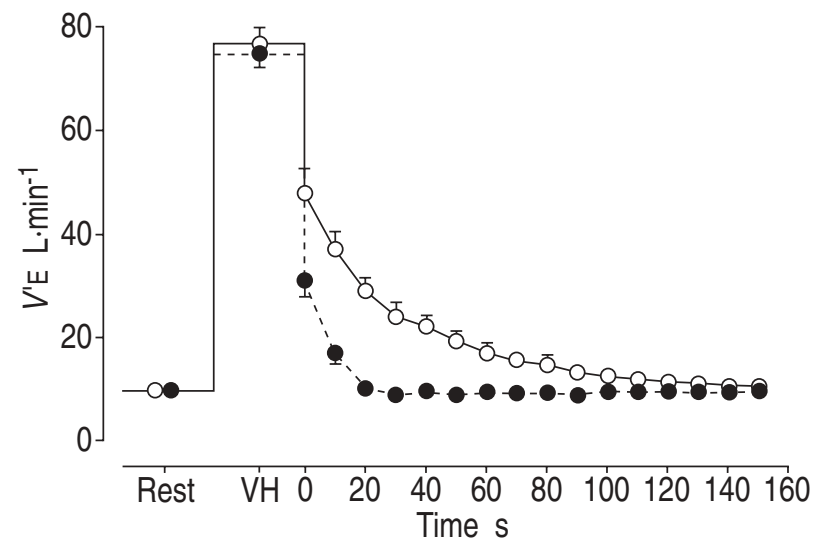

Fig. 1. - Mean ( \pm SEM) minute ventilation $\left(V^{\prime} \mathrm{E}\right)$ measured at rest, during voluntary hyperventilation $(\mathrm{VH})$ and during the $150 \mathrm{~s}$ following cessation of voluntary hyperventilation in 20 hypertensive patients $(\bullet)$ and in 12 healthy subjects $(O)$.

0.016 and $2.79 \pm 0.021 \mathrm{kPa}$ in hypertensive patients and controls, respectively. At the end of the hyperventilation period, during the $\mathrm{CO}$ measurement, $P \mathrm{ET}, \mathrm{CO}_{2}$ rose to similar values in both groups $(4.50 \pm 0.055$ and $4.55 \pm 0.082 \mathrm{kPa}$, in hypertensives and controls, respectively).

After voluntary hyperventilation, $V^{\prime} \mathrm{E}$ fell immediately to basal values in seven out of 20 hypertensives; in the remaining 13 patients, the decay of $V^{\prime} \mathrm{E}$ ( $\tau$ range: $0.2-8.4 \mathrm{~s}$ ) was faster than in the controls ( $\tau$ range: $12-59 \mathrm{~s}$ ). The mean \pm SEM of $\tau$ obtained in the whole group of hypertensive patients $(n=20)$ was significantly lower than in the controls
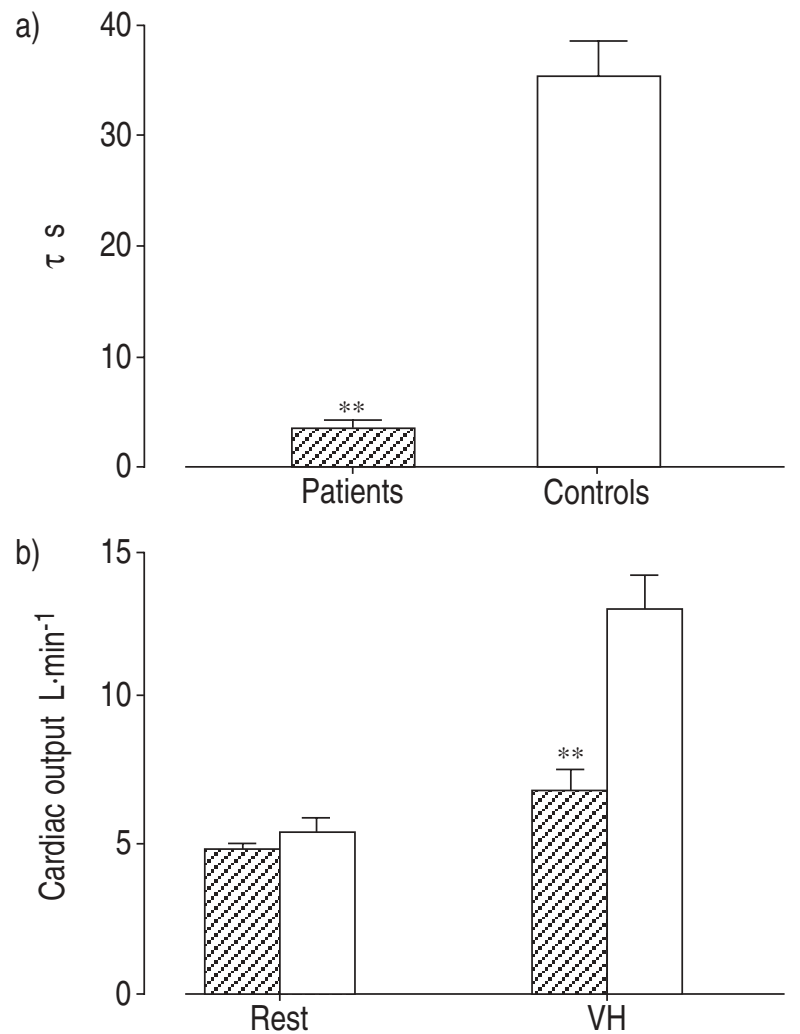

Fig. 2. - a) Mean ( \pm SEM) time constant $(\tau)$ of decay of posthyperventilation hyperpnoea obtained in hypertensive patients $(Q ; n=20)$ and in healthy subjects $(\square ; n=12)$. b) Mean ( $\square$ SEM) cardiac output at rest and during voluntary hyperventilation $(\mathrm{VH})$ in hypertensive patients $(\mathrm{n}=20)$ and in healthy subjects $(\mathrm{n}=12)$. **: $\mathrm{p}<0.01$. 


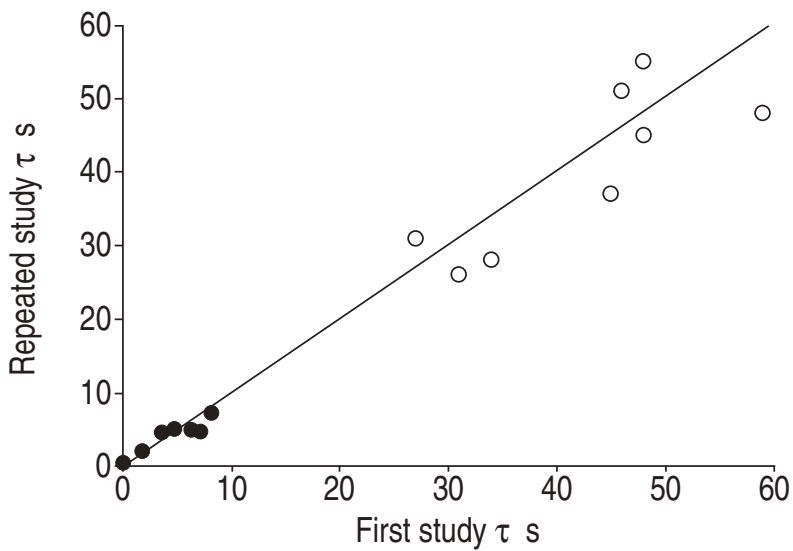

Fig. 3. - Identity plot of the time constant $(\tau)$ of decay of posthyperventilation hyperpnoea measured in the first study and after a two-hour interval (repeated study) in eight hypertensive patients $(\bullet)$ and in eight healthy subjects $(\mathrm{O})$.

( $<<0.01$; fig. 2). Basal CO was not significantly different in hypertensives as compared with controls $(4.8 \pm 0.5$ versus $5.4 \pm 0.2 \mathrm{~L} \cdot \mathrm{min}^{-1}$, respectively), whereas during hyperventilation, it rose to a lesser extent in hypertensives as compared with controls $\left(6.8 \pm 0.7\right.$ versus $12.9 \pm 1.1 \mathrm{~L} \cdot \mathrm{min}^{-1}$, respectively; $\mathrm{p}<0.01$; fig. 2 ). In hypertensive patients, there was a significant linear relationship between changes in $\mathrm{CO}$ during voluntary hyperventilation and $\tau(\mathrm{r}=0.646$; $\mathrm{n}=$ $20 ; \mathrm{p}=0.002$ ).

Identity plots of $\tau$, measured in both hypertensives and healthy subjects, in the first study and after a two-hour interval are reported in figure 3 . The duration of the PHVH was reproducible in both groups, the intra-individual coefficient of variation of $\tau$ ranging from $2.4-11.7 \%$.

During voluntary hyperventilation, the arterial blood pressure fell slightly from $175 / 106 \pm 10 / 8$ to $168 / 93 \pm 9 / 5$ $\mathrm{mmHg}$, nonsignificant (Ns) in hypertensive patients and from $124 / 78 \pm 8 / 4$ to $118 / 74 \pm 7 / 4 \mathrm{mmHg}$ (Ns) in controls. The heart rate during voluntary hyperventilation rose significantly from $78.4 \pm 6.5$ to $94.7 \pm 7.2$ beats $\cdot \mathrm{min}^{-1}$ in hypertensives $(\mathrm{p}<0.01)$, and from $74.9 \pm 5.3$ to $98.6 \pm 6.7$ beats. $\mathrm{min}^{-1}$ $(p<0.01)$ in controls. The differences between the groups for blood pressure and heart rate changes were not significant.

\section{Discussion}

In this study, it was demonstrated that hypertensive patients have a shorter duration of PHVH as compared to control healthy subjects. This phenomenon was reproducible and was associated with a lesser increase in CO during voluntary hyperventilation.

PHVH is a well-known phenomenon occurring in healthy subjects after a short period of sustained voluntary hyperventilation. The activation of reverberating circuits of neurons in the respiratory centre area has been hypothesized to be a major determinant of the progressive decay of $V^{\prime} \mathrm{E}$ occurring after cessation of voluntary hyperventilation [11]. It is conceivable that this neural mechanism, associated with active hyperventilation, supplies sufficient neural input to the respiratory centres in order to prevent apnoea caused by the decrease in chemoreceptor activity due to the decreased levels of arterial carbon dioxide tension that occur during hyperventilation [11].

It is well established that in healthy subjects, voluntary hyperventilation is associated with a substantial increase in $\mathrm{CO}$ [8]. Indeed, the respiratory alkalosis caused by hyperventilation induces a decrease in pulmonary vascular resistance, yielding, in turn, an increase in CO [12, 13]. Another mechanism contributing to this increase in $\mathrm{CO}$ is the rise in venous return along with the improvement in left ventricular function due to rapid swings in intrathoracic pressure associated with hyperventilation. A second aspect of the integration between $V^{\prime} \mathrm{E}$ and $\mathrm{CO}$ should be taken into account. It has been pointed out that the increase in $\mathrm{CO}$ is followed by a rise in resting $V^{\mathrm{E}} \mathrm{E}$ as well as in respiratory frequency in dogs $[5,6]$, thus indicating that changes in $\mathrm{CO}$ can affect the ventilatory output. In addition, it has been postulated that the increase in $\mathrm{CO}$ occurring during voluntary hyperventilation could be partially responsible for the occurrence of PHVH [2]. Our results, showing that the smaller increase in $\mathrm{CO}$ during hyperventilation is followed by a shorter duration of $\mathrm{PHVH}$ in patients with essential hypertension, and that there was a significant correlation between changes in $\mathrm{CO}$ and duration of PHVH in hypertensives, substantially support this hypothesis and suggest a causal relationship between these two phenomena. The small increase in $\mathrm{CO}$ in hypertensive patients observed in our study is in agreement with previous observations showing that hypertensive patients have a less pronounced increase in $\mathrm{CO}$ during exercise as a consequence of the poor functional reserve of the left ventricle $[9,14]$. In our study $\mathrm{CO}$, was measured noninvasively by the indirect Fick method because a more invasive procedure would not have been justified for the purpose of the study. In addition, the indirect Fick method is widely accepted for the assessment of CO [10, 15, 16], and it has been used for measuring $\mathrm{CO}$ during voluntary hyperventilation in healthy subjects [8].

Mechanisms other than $\mathrm{CO}$ changes may be involved in the regulation of $\mathrm{PHVH}$. For example, $\mathrm{PET}, \mathrm{CO}_{2}$ levels as well as respiratory frequency during voluntary hyperventilation are two important factors affecting the duration of PHVH [2, 3]. In our study, however, both hypertensives and controls showed similar levels of $P \mathrm{ET}, \mathrm{CO}_{2}, V^{\prime} \mathrm{E}$, and respiratory frequency during hyperventilation, thus implying that these factors can be ruled out as determinants of the different durations of PHVH in the two groups. Furthermore, $\mathrm{PET}, \mathrm{CO}_{2}$ at the end of hyperventilation during the $\mathrm{CO}$ measurements was similar in hypertensives and controls. It should also be emphasized that the pattern of the decay of $V^{\prime} \mathrm{E}$ after voluntary hyperventilation was highly reproducible, as assessed by the $\tau$ values obtained at two-hour intervals, both in healthy subjects and in hypertensive patients. Finally, the possibility that cerebrovascular damage associated with hypertension can affect the activity of neural centres responsible for the after discharge cannot be excluded. We have previously demonstrated that hypertensive patients exhibit a faster recovery from cerebral vasoconstriction caused by hyperventilationinduced hypocapnia, indicating an alteration in cerebrovascular reactivity [17]. However, the possibility that these or other cerebrovascular alterations can affect the respiratory centres remains purely speculative.

This study represents the first observation that hypertensive patients exhibit alterations in the control of breathing 
characterized by a shorter duration of posthyperventilation hyperpnoea after voluntary hyperventilation. Furthermore, our results support the notion that cardiac output and minute ventilation are strongly integrated and indicate that the alteration in cardiac function has important consequences on the control of breathing in essential hypertension. Our findings that hypertensive patients, who have a less pronounced rise in cardiac output, have a much shorter posthyperventilation hyperpnoea are in agreement with previous observations showing that spontaneous hyperventilation during sleep is followed by central sleep apnoea or periodic breathing in patients with congestive heart failure [18]. Our data indicate that patients with essential hypertension are more prone to alterations of the mechanisms involved in the control of breathing. We suggest that these alterations could be responsible for changes in breathing pattern during sleep and central apnoea episodes occurring in hypertensive patients during sleep.

\section{References}

1. Tawadrous FD, Eldridge FL. Posthyperventilation breathing patterns after active hyperventilation in man. $J$ Appl Physiol 1974; 37: 353-356.

2. Swanson GD, Denham SW, Bellville JW. Posthyperventilation isocapnic hyperpnea. J Appl Physiol 1976; 40: 592596.

3. Folgering H, Durlinger M. Time course of posthyperventilation breathing in humans depends on alveolar $\mathrm{CO}_{2}$ tension. J Appl Physiol: Respirat Environ Exercise Physiol 1983; 54: 809-813.

4. Takano N. Change in time course of post hyperventilation hyperpnoea during menstrual cycle. J Appl Physiol 1988; 64: 2631-2635.

5. Wasserman K, Whipp BJ, Castagna J. Cardiodynamic hyperpnoea: hyperpnoea secondary to cardiac output increase. J Appl Physiol 1974; 36: 457-464.

6. Lloyd TC Jr. Control of breathing in the anaesthetized dog by a left-heart baroreflex. J Appl Physiol 1986; 61:
2095-2101.

7. Donevan RE, Anderson NM, Sekelj P, Papp O, McGregor $M$. Influence of voluntary hyperventilation on cardiac output. J Appl Physiol 1962; 17: 487-491.

8. Anholm JD, Johnson RL, Ramanathan M. Changes in cardiac output during sustained maximal ventilation in humans. J Appl Physiol 1987; 63: 181-187.

9. Wilkstrand J. Diastolic function of the hypertrophied left ventricle in primary hypertension. Clin Physiol 1986; 6: 115-127.

10. Wilmore JH, Farrell PA, Norton AC, et al. An automated, indirect assessment of cardiac output during rest and exercise. J Appl Physiol 1982, 52: 1493-1497.

11. Eldridge FL. Central neural respiratory stimulatory effect of active respiration. J Appl Physiol 1974; 37: 723-735.

12. Rokseth R. Effect of altered carbon dioxide tension and $\mathrm{pH}$ on the human pulmonary circulation. Scand J Clin Lab Invest 1966; 90: Suppl. 1, 9-78.

13. Malik AB, Kidd BS. The independent effect of changes in $\mathrm{H}^{+}$and $\mathrm{CO}_{2}$ concentrations on pulmonary hemodynamics of intact dogs. Can J Physiol Pharmacol 1973; 51: 134-147.

14. Fouad FM. Left ventricular diastolic function in hypertensive patients. Circulation 1987; 75: Suppl. I; I48-I55.

15. Mujesan G, Sorbini CA, Solinas E, Grassi V, Casucci G, Petz E. Comparison of $\mathrm{CO}_{2}$ rebreathing and Fick methods for determining cardiac output. J Appl Physiol 1968; 24: 424-429.

16. Mahler DA, Matthay RA, Snyder PE, Neff RK, Loke J. Determination of cardiac output at rest and during exercise by carbon dioxide rebreathing method in obstructive airway disease. Am Rev Respir Dis 1985; 131: 73-78.

17. Malatino LS, Bellofiore S, Costa MP, Lo Manto G, Finocchiaro F, Di Maria GU. Cerebral blood flow velocity after hyperventilation-induced vasoconstriction in hypertensive patients. Stroke 1992; 23: 1728-1732.

18. Naughton M, Benard D, Tam A, Rutherford R, Bradley TD. Role of hyperventilation in the pathogenesis of central sleep apnoeas in patients with congestive heart failure. Am Rev Respir Dis 1993; 148: 330-338. 